\title{
EXECUTIVE INFORMATION SYSTEMS AND THE TOP-OFFICERS' ROLES: AN EXPLORATORY STUDY OF USER-BEHAVIOUR MODEL AND LESSONS LEARNT
}

\author{
Emmanuel Matthew Ikart \\ School of Management, Marketing \& Industrial Relations \\ University of Wollongong, NSW 2522 \\ Email:emi01@uow.edu.au
}

\begin{abstract}
In recent years a number of organisations have implemented executive information systems (EIS) in order to improve the performance of their executives' jobs. Although the use of EIS is important in executives' work, the majority of executives are unwilling to use EIS applications because of their design flaws. By using social factors, habits and facilitation condition variables from Triandis' framework, this paper extends the Technology Acceptance Model (TAM) to derive useful variables to address the problem of the low usage of EIS by executives. This paper reports on research in progress in Australia on the adoption and usage of EIS by executives. The preliminary results suggest that executives' experiences in EIS positively relates to their experiences in computer-based information systems. The results also suggest there is a high degree of perceived usefulness, perceived ease of use as well as positive attitudes towards using EIS. Further, the results suggest that executives consider social factors in using EIS in their work. Moreover, the results suggest that facilitating conditions such as EIS development process, EIS management process and organisational environment are strongly related to the adoption and usage of EIS by executives. Finally, the results suggest a higher degree of EIS usage by middle managers than top-level managers, which an EIS was meant to support.
\end{abstract}

Keywords: EIS, Cultural, Social, Organisational factors, Executives, Theoretical Foundation, User acceptance, Usage

\section{INTRODUCTION}

Executive Information Systems (EIS) are computerised systems that provide executives with on-line easy access to internal and external information relevant to their business success factors (Rainer and Watson, 1995). The aim of EIS is to bring information from the external environment and all parts of an organisation and present it in a way that is meaningful to executive users (McBride, 1997; Ikart, 2004a, 2004b). Nonetheless, the actual engagement or use of these systems by executives is relatively low (Young \& Watson, 1995; Thodenius, 1995; Fitzgerald, 1998).

In recent times the use of EIS in organisations has spread to managers at various levels (Leidner \& Elam, 1994; Nord \& Nord, 1995; Fitzgerald, 1998; Vlahos et al., 2000; Salmeron, 2002; Singh et al., 2002). Although this spread has given EIS new names such as enterprise information system, business intelligence (BI) software and Balanced Scorecard (Liang \& Miranda, 2001, Ikart 2004a, 2004b), the problem of underutilisation by the executives remains unresolved. In Fitzgerald and Murphy (1994) for instance, the usage gap between executives and middle managers was $36 \%$. They found that only $32 \%$ of EIS users were at executive level while the majority $(68 \%)$ of users were at middle management level. This finding was confirmed by a further study by Fitzgerald (1998). These findings suggest a higher degree of utilisation of EIS at the middle management level, than at the strategic management level, which is the level an EIS was meant to support.

Because the implementation and operations of EIS are more or less championed by senior 
executives with broad and general management support (Thodenius, 1995; McBride, 1997; Fitzgerald, 1998; Poon \& Wagner, 2001) one would expect a significant level of use by the senior management. But the actual use by senior managers is very small (Kraemer et al., 1993).

A number of researchers (e.g., Robey, 1979; Szajna, 1993; Davis, 1993; Young \& Watson, 1995; Mao, 2002) have investigated organisational and technological factors that determine user acceptance of IS including EIS. Although these research efforts have provided some valuable results, they have been constrained by lack of appropriate reference theoretical foundations and variables for key determinants of user acceptance and use of information systems (Ikart, 2004a). Kling (1991) who studied the social impact of human computer argued that, " in order to identify the social impact of computing one must have at least implicitly a theory of the casual power that computerised systems can exert upon individuals, groups, organisations, institutions, social networks, social world and other social entities" (p. 151).

Several studies (Bergeron et al., 1995; Kumar \& Palvia, 2001; Singh et al., 2002) have reported the growing popularity of EIS in organisations as new concepts such as enterprise resources planning (ERP), data warehousing, data mining, web-base portal to "dashboard" and "scorecards" and the on-line analytical processing (OLAP) engine have paved the way for a new era of managing corporate data. Despite these, the underutilisation of EIS by senior managers remained an important challenge to user organisations. "Top officers don't use executive information systems" (Wildt, 1991 p. 38).

The characteristics of EIS including the ability to move freely between a high-level view of data and a detailed view ('drill-down') a concentration on data relating to key performance indicators and critical success factors, the ability to highlight exceptions and variances automatically and to present information in graphical, tabular, textual and colours to the executives make EIS a suitable tool for executives' work (McBride, 1979; Ikart, 2004a, 2004b).

The motivation for this paper is the marked limited research on the actual use of EIS by executives and the lack of an appropriate reference theoretical foundation for individual, organisational, social and cultural variables in determining the factors for user acceptance and use of EIS. The primary focus of the paper is to investigate organisational, social, cultural and individual factors that can explain executives' behaviour towards the adoption and usage of EIS in organisational settings. Furthermore, the paper aims to highlight and explain the importance of these factors in determining the adoption and usage of EIS by executives.

The potential contribution of this paper is the research model based on organisational behaviour theories which provides a future direction in explaining executives' behaviour towards EIS adoption and usage. The preliminary results reported in this paper provide better understanding of the behaviour of executives in using EIS. Moreover, the results would assist EIS developers to understand the core information processing requirements for executives' tasks for which they are building EIS in order to implement appropriate system functionalities to support those tasks. In an academic sense, the new framework and research model will assist researchers to further explain human behaviour towards IS acceptance and usage.

The remainder of the paper is organised as follows. First, we present different definitions of EIS and choose the definition suitable for the present study. Second, we examine the nature of executives' work and how EIS fits-in. Third, we examine past research studies on EIS usage. Fourth, we address the research problem and research questions of the study. 
Further, we look at the theoretical perspective in IS research including TAM and its implications in explaining user acceptance and use of IS as well as Triandis' (1979) framework variables such as habits, social factors and facilitating conditions relevant for the study. Next, we develop the research model for the study followed by the research hypotheses and implications from empirical studies. Finally, we provide the research methodology, data collection methods, questionnaire design, the preliminary results, conclusions and future direction.

\section{DEFINITION OF EIS}

What is an EIS? The definition of an EIS varies according to the weight attached to the three elements in the name itself. Executives' roles differ in terms of personal management styles, company size and hierarchy (Nord and Nord, 1995). According to Rockart and De Long (1992), an EIS is the routine use of a computer terminal for any business function. The users are either the CEO or a member of the senior management team reporting directly to him or her. Executive support systems can be implemented at the corporate level and/or divisional level. Bergeron et al (1995) also share the same view.

Thierauf, (1991) provides yet another classic definition of EIS as, "computer-based systems with data sources and programs which locate the desired data, place it in a common format, massage it into useful form and present it as a useful information for the executive" (p. 9).

Supporting the contention, Turban, (1993) defines an EIS as "a computer based system that serves the information needs of the top executive. It provides rapid access to timely information and direct access to management reports. It is user friendly supported by graphics and provides exceptions reporting and "drill-down" capabilities. It is connectable to on-line information services and electronic mails" (p.394).

For the purpose of the present study, EIS is defined as a computerised system that provides executives with on-line easy access to internal and external information relevant to their critical business success factors (Rainer and Watson, 1995).

Figure 1 below depicts a general model of an organisational EIS. It shows how management collects the internal transaction data. And how data from the external source can be retrieved and stored in an organisational database. Data from these two sources can then be transformed and/or manipulated on EIS screens into formats that facilitate the development of management reports and answers to queries. Executives are particularly interested in summaries and compilations of information. This transformation provides meaningful formats in terms of colours, graphics and text to aid executive users (Watson et al, 1991; Nord and Nord, 1995). 


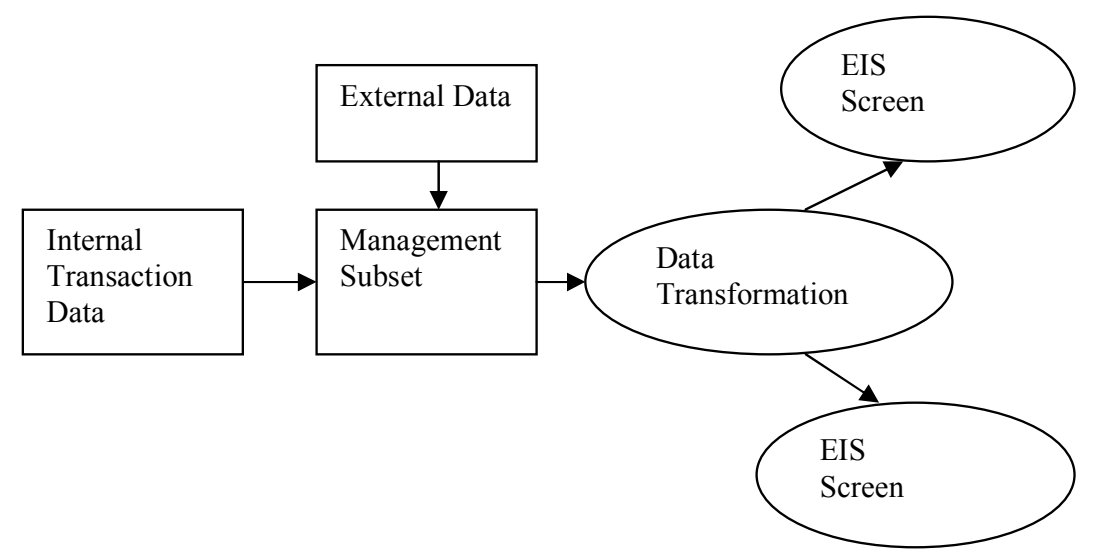

Figure 1: A Model of an EIS Adapted from Nord J.\& Nord G.1995, p.96

\section{Executives' Work and How EIS Fits-in}

The nature of executives' work has been characterised as brevity, variety, interrupted and fragmented (e.g., Mintzberg, 1973; Kotter, 1982). As referenced in Ditsa, (2002), "there is no position in the organisational hierarchy that is less understood than that of executives" (p.184). Moreover, the functions, and how those functions are performed, vary between organisations and between executives within an organisation. Indeed, one of the many reasons of EIS failures in organisations has been the lack of understanding of executives' work by the EIS developers. Executives' work has traditionally been related to identifying problems and opportunities and making the decisions of what to do with those problems and opportunities. In addition to playing leadership roles expected of them much of the work of executives revolve around developing agendas, goals, strategies that may not be documented, establishing networks and developing corporate relationships with people inside and outside their organisations who may play a role in developing future agenda (Ditsa, 2002). This section examines the nature of executives' work in terms of 1), Kotter's "job demands" agenda setting and "network building" 2), Anthony's planning and control model and 3), Mintzberg's roles model theory.

\section{Kotter's "Job Demands" Agenda Setting and "Network Building"}

Kotter (1982) studied fifteen executives through observation, questionnaire and interviews in nine USA corporations. He identified the job demands of executives and categorized them into agenda setting, network building and execution. According to him, in agendasetting, executives developed loosely connected goals and plans relating to short, medium and long terms responsibilities in the form of formal documentations and ideas in their heads. This is based on executives' knowledge of their work and information they gathered through primary discussions with people. In network building, they develop networks of relationship with people such as subordinates, peers, bosses, outsiders and those they feel would make an important contribution to a successful implementation of the agendas. At 
the execution level, executives mobilise support from the network for the implementation of the agendas.

\section{Anthony's Planning and Control Model}

In his work, Anthony (1992) suggests that executives' roles fall into strategic planning, management control and task control. In strategic planning executives determine organisational goals and develop strategies for achieving the goals. In management control, they influence the participants to implement the established strategies. In task control, they ensure specific tasks are handled with effectiveness and efficiency.

Each of these activities requires different types of information. Although at the strategic planning level executives rely on summary information from external sources, at the task control level, they rely on detailed information generated within their organisations. The information for management control falls within strategic planning and task control levels (Ditsa, 2003).

\section{Mintzberg's Roles Model Theory}

In his research work, Mintzberg (1973) describes executives' jobs in terms of ten roles. He categorises these roles into three major roles such as interpersonal, informational and decisional roles. He subdivides the interpersonal role into figurehead, leadership and liaison roles. Furthermore, he subdivides the informational role into monitor, disseminator and spokesperson roles. The decisonal role, he subdivides into entrepreneur, disturbance handler, and resources allocator and negotiator roles. In our opinion, Mintzberg's roles model best characterises executives' roles. Moreover, these categorisations involve dealing with information. EIS have been designed to support executives in these roles.

EIS clearly fit into Mintzberg's roles model theory of executives. Perhaps, the advancement in IS software and hardware such as Web browser, CD-ROM, Internet, enterprise resources planning, data mining and data warehousing which are common features of EIS contribute significantly to this fitness (Thodenius, 1995; Singh et al., 2002).

Although EIS may not completely replace the ways that executives' acquire and use their information such as intuition and face-to-face (Mintzberg, 1973), they support executives' work and relieve executives to focus on other unstructured problems. EIS can capture both "hard" and "soft" forms of information from the internal and external business environments. The former refers to numbers and figures while the latter refers to explanations of the numbers presented e.g., hearsay, rumours and opinions. Strategically, the soft part of information provides additional meanings and richness to the hard data.

Further, the capabilities of EIS enable executives to quickly search and scan their organisational environment for threats and opportunities for immediate and appropriate decisions. EIS are business tools that support and improve the decision-making process of the executive by providing the basic usable and relevant information from both the internal and external environments of organisation. Moreover, because executives devote much of their time to acquire and analyse information through interactions with people and processing of documents, EIS are designed to save considerable amount of executives' time by facilitating the collection, retrieval, storage and analyse of information. The "what-if" analytical capability of EIS combined with executives' decision-making imagination and judgment support executives to arrive at a decision easily and with accuracy. 


\section{PAST RESEARCH STUDIES ON EIS USAGE}

Research studies on EIS usage can be broken into five major areas as follows: (i) Factors influencing and explaining use, (ii) Overall benefits from EIS, (iii) Pattern of use and frequency of use, (iv) Impact of EIS on managerial activities, and (v) Emergence of EIS. In the classifications below (Table 1), the majority of research on EIS has been exploratory instead of theory testing. Only a limited number of studies (e.g., Bergeron et al., 1995; Ditsa, 2003) in research area (i) employed appropriate reference theories to gain insight into factors influencing the actual use of the systems by senior managers. Without appropriate reference theories, it will be difficult to realise the importance of the other four focussed areas.

\begin{tabular}{|c|c|}
\hline$\underline{\text { Research Areas }}$ & Reference \\
\hline $\begin{array}{l}\text { Factors influencing/explaining } \\
\text { EIS use }\end{array}$ & $\begin{array}{l}\text { Young \& Watson, 1995; Rainer \& Watson, 1995; } \\
\text { Bergeron, et al., 1995; Basu et al., 2000; Poon \& } \\
\text { Wagner, 2001; Singh et al., 2002; Ditsa, } 2003\end{array}$ \\
\hline ii Overall benefits from EIS & $\begin{array}{l}\text { Nord \& Nord, 1995; Kelly, 1994; McBride, 1997; } \\
\text { Nanhakumar \& Jones, } 1997\end{array}$ \\
\hline $\begin{array}{l}\text { iii Patterns of use \& frequency of } \\
\text { use }\end{array}$ & Thodenius, 1995; Seeley \& Targett, 1999; \\
\hline v. Emergence of EIS & $\begin{array}{l}\text { Rockart and Delong, 1992; Laidner \& Elam, 1994; } \\
\text { Handzic, 1997; Wheeler, 1996; Stein \& Nasib, } \\
\text { 1997; } \\
\text { Liang \& Miranda, 2001; Kumar \& Palvia, 2001; } \\
\text { Salmeron, 2002. }\end{array}$ \\
\hline & $\begin{array}{l}\text { Houdeshel \& Watson, 1987; Rockart \& Treacy, } \\
\text { 1992; Fitzgerald \& Murphy, 1994; Fitzgerald, 1998, }\end{array}$ \\
\hline
\end{tabular}

Table 1: Classification of EIS Usage Research

Nandhakumar and Jones (1997) witnessed an EIS development project in their in-depth study of the development methods in organisations where potential executive users were not involved in the design phases. As a result, they suggest that there should be better theoretical conceptualisation of the dynamic relationship between the developers and executives to assist in understanding how the relationship shapes, and is shaped by various constraints.

McBride (1997) studied the progress of an EIS project within a manufacturing organisation in the UK over a 9-year period. The study demonstrates the importance of the interaction between the business environment, the organisational environment and the perceptions and interpretations of events by stakeholders on the success or failure of EIS. Particularly, it illustrates the importance of the organisational context and the dynamic nature of the social, economic and technical factors critical in shaping acceptance and use of EIS in organisations. 
The above two studies suggest that the roots of the success or failure of IS including EIS can be attributed to social, cultural and organisational factors and not technical factors alone.

\section{RESEARCH PROBLEM AND QUESTIONS}

The research problem that this study seeks to address is the low usage of EIS in organisations by executives. To provide a solution to the research problem, a research model from organisational behaviour as a theoretical foundation is employed. The main objective of this study is therefore to investigate and examine cultural, social, and organisational factors that explain senior managers' behaviour in accepting and using EIS. The following research questions are addressed in this study to provide answers to the research problem. The next subheading examines the theoretical foundation for the study.

- What are the social, cultural and organisational factors that explain senior managers' behaviour towards using EIS?

- What are the importances of these factors in determining EIS usage by senior managers of organisation?

\section{THEORETICAL PERSPECTIVE IN IS RESEARCH}

A number of theories are used in IS research areas to explain individuals' behaviour towards computers. Candidates among these theories include, Task Technology Fit model (e.g., Dishaw and Strong, 1997); Institutional Theory, Coordination Theory and Organisational Complexity Model (e.g., Yager, 1997); Contingency Model (e.g., Lauer and Rajagopalan, 2002); Variance Theory and Process Theory (e.g., Seeley and Targett, 1999); General System Theory (e.g., Raisinghani and Schkade, 1997); Diffusion Theory (e.g Raisinghani and Schkade, 1997; Mao, 2002); Activity Theory (e.g., Verenikina and Gould, 1997) and the Theory of Plan Behaviour (Mathieson, 1991; Taylor and Todd, 1995).

These theories have been acknowledged in IS research because they assist researchers to gain a useful insight into the reaction of people towards computer technology and factors enabling the reactions. For instance, Activity Theory aims to explain the connection between human psychology and computer interface design in a social work environment. This establishes the relationship between human computer interactions and computer interface design by taking into consideration the context of the work environment (Verenikina and Gould, 1997). Also, the Task-Technology Fit Model aims to match the capability of the technology to the demand of the technology in a work environment (Dishaw and Strong, 1997).

Unfortunately, none of the above theories examines explicitly organisational contextual factors such as cultural, social and organisational variables that can explain executives' behaviour towards EIS adoption and use because they have insufficient reference variables. The Technology Acceptance Model (TAM) (Davis, 1989, 1993 Davis et al., 1992), which is derived from the Theory of Reasoned Action (TRA) (Fishbein, 1979), has been widely used, as a theoretical foundation to explain IS acceptance and usage. Moreover, Triandis' (1979) framework has been used as a theoretical foundation by previous studies (e.g., Bergeron et al., 1995; Ditsa, 2002, 2003) to address explicitly the social, culture and organisational factors that can explain executives' behaviour towards the adoption and usage of EIS for strategic activities. Both TAM and Triandis' framework have separately guided several researchers (Davis 1989; Davis, et al., 1992, Davis, 1993; Dishaw \& Strong, 
1997; Srivihok, 1999; Kwon \& Chidambaram, 2000; Mao, 2002; Thompson et al., 1991; Bergeron et al., 1995; Ditsa, 2002, 2003) to explain human behaviour towards the adoption and use of computers. This paper uses both TAM and Triandis' framework as theoretical foundations. The paper extends TAM with variables - habits, facilitating conditions and social factors - from Triandis' framework to derive a research model suitable for the adoption and use of EIS by organisational executives.

\section{TECHNOLOGY ACCEPTANCE MODEL (TAM)}

Davis (1986) developed TAM to explain human computer-usage behaviour using Fishbein and Ajzen's (1975) TRA as the theoretical basis. The objective of TAM is to provide an explanation of the determinants of computer acceptance that is capable of explaining the behaviour of users across a broad range of end-user computing and user populations while simultaneously being parsimonious and theoretically justified (Davis, 1989). TAM uses TRA to specify causal linkages between two relevant sets of constructs - perceived usefulness (PU) and perceived ease of use (PEOU) - and user attitude (A), behavioural intention $(\mathrm{BI})$ and actual computer usage behaviour.

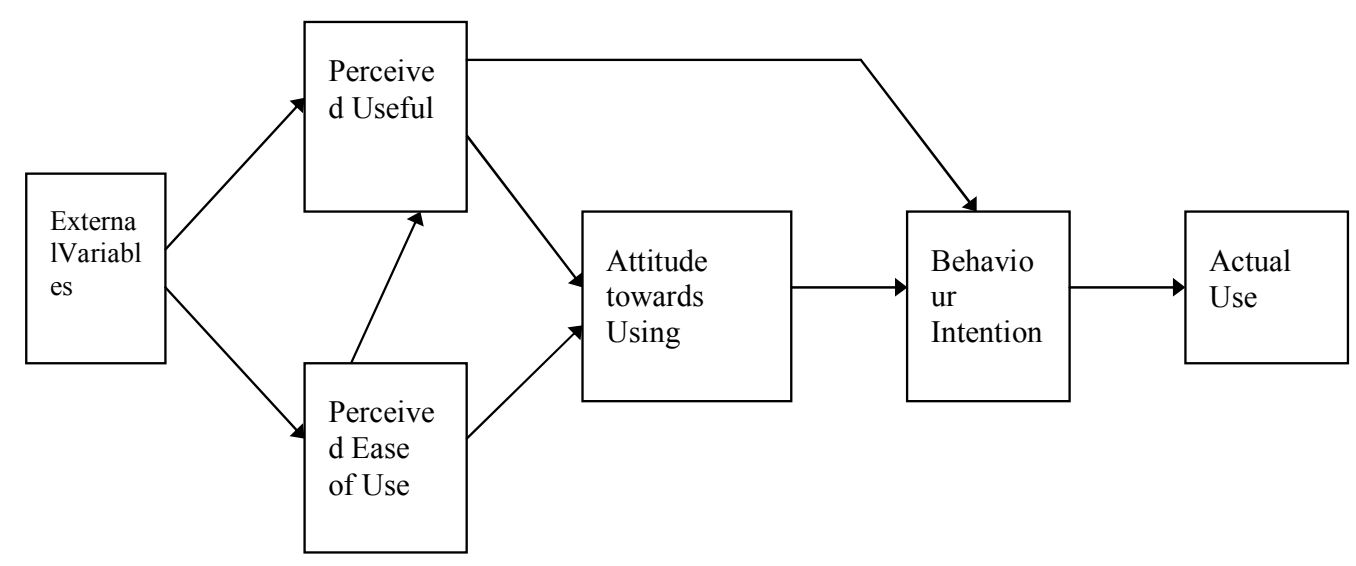

Figure 2: Technology Acceptance Model

Davis et al., (1989, p. 320) define PU as the user's "subjective probability that using a specific application system will increase his/her job performance within an organisation context". Davis defines PEOU as "the degree to which an individual believes that using a particular system would be free of physical and mental effort" (Davis, 1993 p. 447). While PEOU relates to the assessment of the intrinsic characteristics of IT such as ease of use, ease of learning, flexibility and clarity of its interface, $\mathrm{PU}$ on the other hand is a response to user assessment of its extrinsic, i.e., task-oriented, outcomes. That is the manner in which IT helps users achieve task-related objectives, such as task efficiency and effectiveness (Gefen and Straub, 2000). In TAM both PU and PEOU influence an individual's attitude towards using computers. PU and attitude influence the behaviour intention to use the system. Actual system use is predicted by the behaviour intention. Davis et al., (1989) note 
the arrows in TAM in Figure 2 above indicate the probable causality.

A review of scholarly research on IS acceptance and usage suggests that TAM has emerged as the most influential model in this stream of research (Robey, 1996; Davis 1989; Davis et al., 1989, Ikart, 2004a, 2004b) including e-commerce and the adoption of Internet technology (e.g., Gefen and Straub, 2000) as well as, Knowledge management systems (e.g., Money \& Turner, 2004). TAM with its original emphasis on system design characteristics represents an essential theoretical contribution in understanding IS usage and acceptance behaviours (Davis et al., 1989). For instance, Davis (1989) originally examined an email system and file-editor used at the time at IBM Canada and found the PEOU and PU of TAM to be significantly correlated with self-reported use of the system. On the contrary however, TAM does not account for habits, facilitating conditions and social factors variables provided by Triandis' framework that influence behaviour.

Davis et al. (1989) realised that the omission of the subjective norm from TAM represents an important area that requires further study. Moreover, they observed that the theoretical basis of TRA makes it difficult to distinguish if behaviour is caused by the influence of referent on one's intent or by one's own attitude. Davis (1986) for instance noted that "the subject may want to do what Referent X thinks he/she should do, not because of X's influence, but because the act is consistent with the subject's own [attitude]". Thus, Davis and Davis et al. underscored the importance of social norms that can explain behaviour. Nonetheless, they highlighted the importance of the development knowledge from TAM. In this paper we use TAM as the basis of the conceptual model and incorporate social factors, habits and facilitating conditions from Triandis' framework as an extension. We examine the selected Triandis' (1979) framework variables that are relevant to the paper in the next section.

\section{TRIANDIS’ THEORETICAL FRAMEWORK}

Triandis (1979) presents a theoretical framework with a central theme which focuses on the relationships of values, attitude, and other acquired behavioural dispositions to action or behaviour. The framework defines the relationship involving these concepts. The variables to be used from Triandis' framework for the study are: Social factor, Habits and Facilitating conditions. This study examines this subset of Triandis' framework. For a thorough discussion of the model, the reader should refer to Triandis (1979).

Habits: Triandis defines habits as "situation-behaviour sequences that are or have become automatic such that they occur without self-instruction" (p. 204).

Facilitating conditions: He defines facilitating conditions as "objective factors which are out there in the geographical environment such that several judges or observers can agree make an act easy to do" (p. 205). Acts he says are socially defined patterns of muscle movements.

Social factors: Personality, Triandis states, internalises the cultural way of perceiving the social environment, called the subjective culture of the group. The subjective culture consists of: norms (self-instruction to do what is perceived to be appropriate by members of the culture in certain situations); values (the tendencies to prefer a state of affairs over another; roles (appropriate behaviour by a person holding an office in a group) and, social situation (a behaviour setting where more than one person is present). The internalisation of 
a culture, Triandis argues, forms the social factors that influence the intention to behave. We develop the research model for the study in the next section.

\section{THE RESEARCH MODEL}

The research model (Figure 3 below) is based on TAM plus an extension derived from selected variables - habits, facilitating conditions and social factors - from Triandis' framework. As far as possible all constructs in the research model are operationalised on the basis of previous studies.

Habits consist of EIS experience and ability to use EIS. According to Triandis (1979), habits are what people usually do and the individual's is usually not conscious of the consequences, for example, driving a car. Triandis links habits to an individual past experience and ability to perform a given act. He argues that the habitual nature of a behaviour will have an influence on the individual's response to a given situation. $\mathrm{He}$ further argues that for many behaviours habit is more important than intentions (Triandis, 1979). Accordingly, habits are measured by assessing the number of years of executives' experience in using EIS and their ability to use EIS (Bergeron et al., 1995; Ditsa, 2002, 2003). Shneiderman (1998) classified computer users into novice users, knowledgeable intermittent (casual users) and frequent (expert users). The ability of executives to use EIS will be measured by assessing executive user class.

The facilitating conditions consist of EIS development processes, EIS management processes and organisational environment variables (Ikart, 2004a, 2004b). The first variable is measured by assessing the degree to which the EIS development process in an organization facilitates the use of EIS by the executives using similar questions used by prior studies (e.g., Nandhakumar \& Jones, 1997; Ditsa, 2002, 2003) with five-point Likert scales. The second variable is measured by assessing the degree to which the EIS management process facilitates executives' use of the systems using similar questions used by Nandhakumar and Jones, (1997) and (Ditsa, 2002, 2003) using five point Likert scales. The third variable is measured by assessing the degree to which an organizational environment facilitates the use of EIS by the executives using five similar questions derived from Nandhakumar \& Jones (1997) and, McBride, (1997) and Ditsa (2002, 2003), using five-point Likert scales with 1 for strongly disagree and 5 for strongly agree. These scales are found to be reliable with Cronbach's alpha equal to $0.76,0.74 \& 0.70$ respectively (Ditsa, 2002, 2003).

Social factors consist of subjective norms, subjective roles, subjective values and subjective social situations (Ikart, 2004a,b). In the EIS research domain the social factors have been referred to the executives' work group influence such as, peers; superiors; subordinates and IS directors acting upon their EIS use (Bergeron et al., 1995; Ditsa, 2002, 2003). The social factors variables are measured as follows: The subjective norms (self-instructions to do what is perceived to be correct and appropriate by the work group) are measured by obtaining users' assessment of the influence of the work group upon their behaviour in general (four 5-point Likert scales $(-2$ : strongly disagree, +2 : strongly agree) and multiplied by evaluating their probability that the work group wants them to use EIS (Bergeron et al., 1995; Ditsa, 2003). Subjective roles (an expected correct behaviour from executive users of EIS) are measured by obtaining executives' assessment of their roles and expected behaviours from group work in relation to EIS usage using four 5-point Likert scales. Subjective values (the broad tendencies of the executives' work group to prefer a certain state of affairs over others in relation to EIS usage) are measured by obtaining executives' 
assessment of the work group influence in relation to EIS usage using 5-point Likert scale. Subjective social situations of the workplace setting are measured by obtaining executives' assessment of their interpersonal relationships with their peers, superiors, subordinates, the IS directors and the EIS support group in relation to EIS usage. Five 5-point Likert scales are used for the measure. The scales were obtained from past studies (e.g., Bergeron et al., 1995; Ditsa, 2003) as they appear to be reliable with a Cronbach's alpha of $0.81,0.9$ and 0.86 .

Both the PU and PEOU constructs are operationalised by obtaining users' assessment of their PU and PEOU of EIS based on 12 similar items, six items for each developed, refined and streamlined by Davis (1989) using 7-point Likert scales. Thus, PU and PEOU are adapted from several IS studies (e.g., Davis, 1989; Davis et al., 1989; Matheison, 1991; Venkatesh \& Davis, 1996; Moore \& Benbasat, 1991; Venkatesh et al., 2003). Prior studies (e.g., Davis, 1989) demonstrate the validity and reliability of PU and PEOU with Cronbach alpha of 0.98 and 0.94 respectively (Davis, 1989). The scales have been adjusted to 5-point Likert scale, with one being the negative end of the scale and five being the positive end of the scale. The adjustment was based on both the advice of the statistician consulted in the project design phase and the pre-test results.

Attitude towards usage is measured using five standard 5-point semantic differential scales for operational attitude toward behaviour. The question posed is "All things considered, my using EIS in my job is Good - Bad; Wise - Foolish; Favourable - Unfavourable; Beneficial - Harmful; and Positive - Negative". The scales are 5-point scale with midpoint labelled "Neutral". Although, Azjen \& Fishbein, (1980) suggested five standard 7-point semantic differential rating scales, the scales have been adjusted to 5 based on the advice of the statistician and the outcome of the pre-test. Attitude measurement is therefore adapted from prior IS studies (e.g., Robey, 1979; Davis, 1989; Davis, 1993; Malhotra \& Galletta, 1999; Hubona \& Jones, 2002; Mao, 2002).

The actual system use construct is measured by obtaining users assessment in terms of frequency of use, ('how often'). Similar measures have been used in research on TAM (e.g., Davis, 1989; Davis et al., 1989; Malhotra \& Galletta, 1999; Hubona \& Jones, 2002; Ditsa, 2003). Obtaining users' assessment of the number of times they use EIS in a week and/or their frequency of using EIS is the first measure. The Likert scales used for the measurement are adapted from Davis (1989) and other prior IS research studies (e.g., Davis, 1989; Mathieson, 1991; Moore \& Benbasat, 1991; Adam et al., 1992; Davis, 1993; Venkatesh \& Davis 1996; Mao, 2002; Hubona \& Jones, 2002; Venkatesh et al., 2003). The scales have been adjusted from 7-point to 5-point scales with one being the negative end of the scale and five being the positive end of the scale based on the advice of a statistician and pre-test results.

\section{HYPOTHESES AND IMPLICATIONS OF THE MODEL}

Triandis (1979) states that habits can be measured based on individual experience and ability in performing a given task. Prior research has shown that habits are a strong predictor of behaviour. For instance (Sugar, 1967) as referenced in Thompson et al., (1991) measured the attitudes, norms and habits of college students regarding cigarette smoking. On separate occasions, the same students were offered a cigarette. The strongest single predictor of behaviour was habit, followed by norms and then attitudes. Furthermore, in the EIS domain, habits have been operationalised on the basis of EIS experience and the ability to use EIS (Ditsa, 2002, 2003). In their study, Dambrot et al., (1988), indicate that subjects 
who failed an assembly language programming course had significantly less computer experience than those who did not fail the course. In his study of text editing, Rosson (1983) explains that experience was positively correlated with the number of lines edited per minute. Elkerton and Williges (1984) indicate in their work that experience explains more variance in information search times than do other individual variables. According to Zmud (1979) people's level of education influences their successful use of computer systems. More educated computer users significantly outperformed less educated people in training environments (Davies \& Davies1990). It has been documented that a higher level of education negatively relates to computer anxiety whilst positively relates to favourable computer attitude (Ikart, 2004b). According to Lucas (1978), less educated individuals have more negative attitudes in using computer technology than individuals with better education. Education is effective in overcoming negative attitudes towards computers (Harrison and Rainer, 1992). Hubona and Jones (2002) found in their study of user acceptance of email that length of time since first use and level of education directly influence email usage behaviour. Education and length of time in using information technology parallel individual experience and ability to use computers. Accordingly, we hypothesised that:

H1a: EIS experience will have a positive effect on perceived usefulness of EIS. $H 1 b$ : Ability to use EIS will have a positive effect on perceived usefulness of EIS.

H2a: EIS experience will have a positive effect on perceived ease of use of EIS. H2b: Ability to use EIS will have a positive effect on perceived ease of use of EIS. 


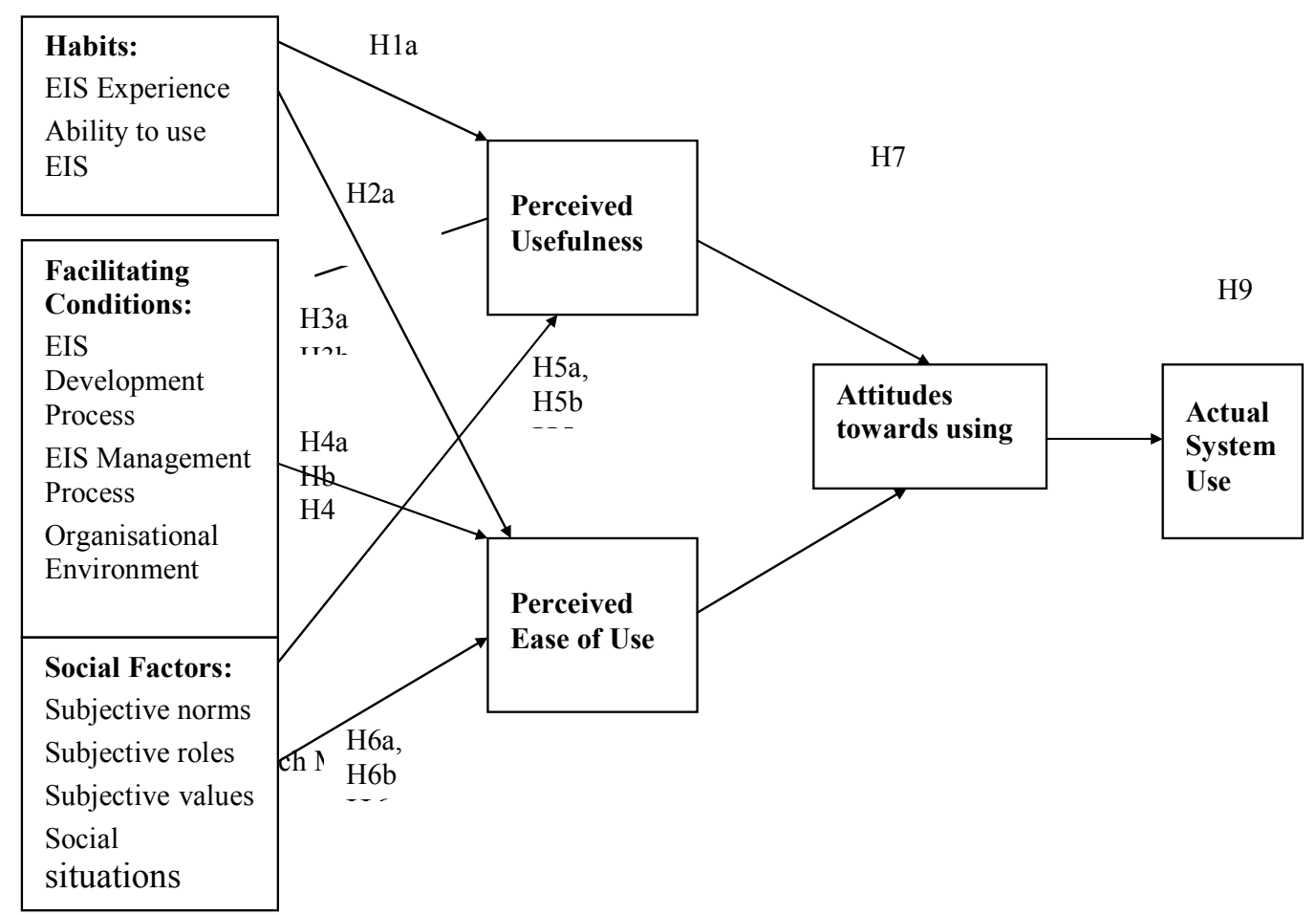

Triandis (1979) argues that behaviour will not occur if objective factors (facilitating conditions) of the geographical environment prevent it. In the information technology domain, facilitating conditions have been operationalised as EIS development process, organisational environment and EIS management process (Ditsa, 2002; 2003). Research efforts in EIS development (e.g., Watson, et al., 1991; Rainer \& Watson, 1995; Srivihok, 1999) have sought to understand the factors contributing to cost-effectiveness of EIS projects in organisations. Findings have linked this research to factors such as general top management support, committed executive sponsor, managing user resistance and expectations, managing system spread and evolution, delivering the first version of the system quickly, employing an evolutional development process, involving users in the development and linking the development to business objectives (Watson, et al., 1991; Nandhakumar \& Jones, 1997; McBride, 1997; Srivihok, 1999; Poon \& Wager, 2001; Ikart, 2004a, 2004b). In addition, it is linked to employing appropriate technology such as hardware and software, IS staff and managing data problems (Kelly, 1994; Rainer \& Watson, 1995; Ikart, 2004a, 2004b). Accordingly, we hypothesised that:

H3a: EIS development processes will have a positive effect on the perceived 
usefulness of EIS.

$H 3 b$ : EIS management processes will have a positive effect on the perceived usefulness of EIS.

H3c: Organisational environment will have a positive effect on the perceived usefulness of EIS.

H4a: EIS development processes will have a positive effect on the perceived ease of use of EIS.

H4b: EIS management processes will have a positive effect on the perceived ease of use of EIS.

H4c: Organisational environment will have a positive effect on the perceived ease of use of EIS

The internalisation of the reference group's subjective culture and specific interpersonal agreements that the individual has made with others, in specific social situations, Triandis (1979) argues, constitutes the social factors that determine behavioural intention. He defines subjective culture as the, "human group characteristic way of viewing the humanmade part of the environment" (p. 208), consisting of ways of categorising experience such as values, norms and roles and social situations. In the information systems research domain, superior, peer and subordinate influences have been strong determinants of subjective norms (Mathieson, 1991; Taylor \& Todd, 1995; Venkatesh \& Davies, 1996; Elkordy, 2000; Ditsa, 2002). Mao (2002) investigated the IT usage behaviour of 80 endusers in four organisations at two points in time based on the TAM model with the subjective norm as a construct of the research model. It was implied that the subjective norms play a more important role in the long run within the group. For instance in the field studies (e.g., Lucas and Spitler, 1999; Karahanna et al, 1999) as referenced in Mao (2002) found subjective norm to be a significant determinant of IS usage. Also, Kwon \& Chidambaram (1999) studied the patterns of cellular phone adoption and usage in an urban setting. They found social pressure to have a positive outcome among professionals as a motivation to adopt and use the systems. Igbaria (1993) studied microcomputer usage in organisations and found social norms to have significant effects on system usage. In his studies, Rogers (1986), indicates the importance of social norms on the rate of the diffusion of innovation.

In the social psychology domain, Lieberman (1956) cited in Westen (1996) examined how workers' attitudes change as a result of job promotions. He measured the attitudes of plant workers and then reassessed after some were promoted to foreman (a management position) and some as shop stewards. Not surprising after the promotions, the foremen were more pro-company than they had been as workers, whereas the shop stewards had become more pro-union. More interestingly however, when the company later experienced financial problems and had to demote the foremen to their previous rank-and-file positions they returned to their original attitudes (Westen, 1996; Ikart, 2004a, 2004b). This shows that individual's attitude has a significant influence on his/her behaviour.

Triandis (1979) argued that a behaviour setting in social situations has time-place coordinates, physical entities and processes and, it evokes particular behaviours that distinguish it from what is outside of it. It has structural features, and exists independently of any particular individual's perception of it. Triandis sets an example of this as a classroom with a particular location and time where members meet. The class has chairs, walls and black boards and in it members act in certain ways including talking, listening, writing, taking notes and others. According to Triandis" work "social situation in a 
behaviour setting is a bounded, self-regulated and orderly system composed of replaceable human and non-human components that interact in a synchronised fashion in carrying out an orderly sequence of events such as the setting program" (Triandis 1979, p. 214). A similar idea is shared in Ikart (2004a).

In EIS studies, (e.g., Bergeron, 1995; Ditsa, 2002, 2003) social factors are defined as the executive's work group (peers, superior, subordinates, IS directors). In several studies social factors have shown strong influence on behaviour and utilisation of IS including EIS (Thompson et al., 1991; Bergeron et al., 1995; Ditsa, 2002, 2003; Venkatesh et al., 2003). This suggests that the social factors of the conceptual model will relate strongly with behaviour. Thus we hypothesised that:

H5a: Subjective norms will have a positive effect on perceived usefulness. H5b: Subjective roles will have a positive effect on perceived usefulness. H5c: Subjective values will have a positive effect on perceived usefulness. H5d: Subjective social situation will have a positive effect on perceived usefulness. H6a: Subjective norms will have a positive effect on perceived ease of use. H6b: Subjective roles will have a positive effect on perceived ease of use. H6c: Subjective values will have a positive effect on perceived ease of use. H6d: Subjective social situation will have a positive effect on perceived ease of use.

Research indicates that voluntary computer usage is driven to a large extent by PU (Davis, et al., 1992). Robey (1979) studied industrial sales forces and observed that users' expected performance impacts of a computerised sales record-keeping system were positively correlated with the measure of actual use of the system. Other MIS studies, (e.g., Davis, 1989; Mathieson, 1991; Davis et al., 1992; Adams et al., 1992; Davis, 1993; Taylor \& Todd, 1995; Venkatesh \& Davis, 1996; Dishaw, \& Strong, 1997; Kwon \& Chidambaram, 2000; Elkordy, 2000; Mao, 2002; Ditsa, 2002, 2003) have shown that PU and PEOU are strong determinants of user acceptance and adoption of computer technology. Research on the adoption of innovation has suggested a relevant role for PU and PEOU. According to Rogers (1986), relative advantage and compatibility are important attributes of innovations affecting adoption. Rogers (1986) suggested a number of sub-dimensions of relative advantage including the degree of economic profitability, decrease in discomfort and saving in time. Also, Davis (1989) argued that compatibility, relative advantage and complexity have the most consistent significant relationships across a broad range of innovation types. PU parallels relative advantage (Mao, 2002) and PEOU parallels compatibility and complexity of innovations (Davis, 1989). This finding is consistent with the finding of Tornatzky and Klein (1982) in their meta-analysis of innovation diffusion literature. Tornatzky and Klein reviewed 75 articles and discovered more than 30 innovation characteristics. They investigated ten major innovation characteristics including: compatibility, relative advantage, complexity, communicability, cost, divisibility, profitability, social approval, observability and trial ability and found compatibility, relative advantage and complexity to strongly measure innovation attributes affecting innovation diffusion. Thus, we hypothesised that:

H7: Perceived usefulness will have a positive effect on the attitudes towards using EIS.

H8: Perceived ease of use will have a positive effect on attitudes towards using EIS 
Fishbein (1979, p. 68) defined attitude as, "a function of beliefs". Fishbein and Ajzen (1975) distinguished between beliefs and attitudes and specified how external stimuli like the objective feature of attitude object such as individuals, situation and social groups can be causally linked to beliefs, attitudes and behaviour. According to Fishbein and Ajzen (1975), individual beliefs about the behaviour, also known as the perceived consequence of the behaviour, refers to an individual's subjective likelihood that performing the behaviour will lead to certain outcomes (p.233). On the other hand, attitudes toward the behaviours are an effective evaluation of the behaviour. Attitude towards the behaviour is determined by an expectancy-value model of beliefs (Fishbein, 1979, p.68) weighted by the evaluations of the consequences (Fishbein and Ajzen, 1975, p.233). In their study, they draw a distinction between two separate attitude constructs such as attitude towards the object and attitude towards the behaviour. The former refers to an individual's effective evaluation of a specified attitude object while the latter refers to an individual's evaluation of a specified behaviour that involves the object (Fishbein \& Ajzen, 1975; Davis, 1993). This paper employs attitude towards the behaviour because research studies (e.g., Ajzen \& Fishbein, 1975; Davis, 1993; Robey, 1979; Dishaw \& Strong, 1997; Galletta \& Malhotra, 1999; Srivihok, 1999; Mao, 2002; Hubona \& Jones, 2002; Lim, 2002; Venkatesh et al., 2003) have shown that attitudes toward the behaviour relate more strongly to a specified behaviour. We therefore hypothesised that:

H9: Executives' Attitudes towards using EIS will have a positive effect on actual use of EIS.

\section{RESEARCH METHODOLOGY}

\section{Data Collection Methods}

The data for the pilot study was collected by mail survey from two large organisations in the Illawarra region of Australia identified as using EIS. The main concern of the pilot was to further pre-test the questionnaire as well as serve as an exploratory study for the main study to validate the research model.

\section{Questionnaire Design}

A six-page questionnaire was designed for the pilot. Each question represented a component of the research model. The questions were selected for their theoretical importance and potential relevance to practice (Ikart, 2004a). The Statistical Consultation Service in the University of Wollongong to verify the statical validity of the research model, hypotheses and questionnaire. The questionnaire was pre-tested on four academics and based on the feedback received from the representatives, some modifications were made to the individual questions and instructions.

The revised questionnaire was then subjected to the next phase of pre-testing with academics and four doctoral students drawn from the Faculty of Commerce at the University of Wollongong where the research is taking place. All comments and suggestions given by them regarding the clarity, validity and consistency of the questions were incorporated into the survey instrument.

A cover letter explaining the purpose of the survey was designed. It was mailed with a prepaid envelope to the participants for the pilot study. The cover letter has a statement 
guaranteeing the confidentiality of the respondents and a statement of how the research has been reviewed by the Human Research Ethics Committee (HREC) as required in Australia. Although there is no widely agreed sample size for a pilot survey, between 12 and 30 subjects is generally recommended (e.g., Hunt et al., 1982). The pilot survey was carried out on a representative sample of 30 executives who actually use EIS. After a follow-up by telephone calls 19 returns were received giving a response rate of 63 percent. The returned questionnaires were carefully examined for signs that respondents had difficulty in understanding the questions. All 19 returned questionnaires were good for analysis. There were some suggestions and comments from respondents, which were noted to improve the questions for the main study

\section{Data Analysis and Preliminary Results}

Due to the size of the data for pilot study, a qualitative analysis of the data was carried out. Among the 19 participants for the pilot, in the gender category, the results show that $73 \%$ (14) were males while $26.3 \%$ (5) were females. In the age category, the modal group from the results was 46 - 55 with $47.36 \%$ (9) followed by 36 - 45 group with $36.84 \%$ (7) participation rate. Although there was no participant from the over 55 years group, participation rates from $18-25$ and $26-35$ groups were the lowest participation rates, with $5.26 \%$ (1) and $10.53 \%$ (2) respectively. At the educational level, the results show that the majority of EIS users are highly educated. As shown in Table 2, while 52.26\% (10) of the participants had a postgraduate degree, approximately $37 \%$ (7) of the participants held an undergraduate degree. But only 5.26\% (1) of the participant held High School and TAFE qualifications respectively. In terms of job position, the results show that while the majority, 47.36\% (9) of the EIS users are middle management position holders, 26.3\% (5) are top management position holders. The finding that the majority of EIS users at organisational levels are middle managers confirms the finding of the study by Fitzgerald (1998) study in the United Kingdom, which also concluded that the majority of EIS users are middle managers rather than the top-level managers, which is the team an EIS is meant to support. 


\begin{tabular}{|l|l|l|l|}
\hline $\begin{array}{l}\text { Demographic } \\
\text { Factors }\end{array}$ & $\begin{array}{l}\text { The valid } \\
\text { Items }\end{array}$ & Frequency & Percent \% \\
\hline \hline Gender & Female & 5 & 26.3 \\
\hline \hline Age & Male & 14 & 73.68 \\
\hline & $18-25$ & 1 & 5.26 \\
\hline & $26-35$ & 2 & 10.53 \\
\hline & $36-45$ & 7 & 36.84 \\
\hline \hline Level of Education & $46-55$ & 9 & 47.36 \\
\hline & Over 55 & 0 & 0 \\
\hline & High School & 1 & 5.26 \\
\hline & TAFE & 1 & 5.26 \\
\hline \hline Job Position & Undergraduate & 7 & 36.84 \\
\hline & Postgraduate & 10 & 52.26 \\
\hline & $\begin{array}{l}\text { Top } \\
\text { management }\end{array}$ & 5 & 26.3 \\
\hline & $\begin{array}{l}\text { Middle } \\
\text { management }\end{array}$ & 9 & 47.36 \\
& $\begin{array}{l}\text { Lower } \\
\text { Management }\end{array}$ & 4 & 21.02 \\
\hline & Others & 1 & 5.26 \\
\hline
\end{tabular}

Table 2 Demographic Factors of Respondents in the pilot $(n=19)$

The preliminary results suggest that first, executives' experience in EIS positively relates to their experience in computer-based information systems (CBIS). Second, the result suggests that although some managers have significant knowledge in EIS due to length of use, executives who have been using EIS applications for a greater length of time have greater knowledge of the systems.

Third, the results suggest a high degree of perceived usefulness, perceived ease of use as well as a positive attitude towards using EIS by executives. This may be due to the value outcome, user-friendliness and clarity of the systems to users.

Furthermore, the results suggest that executives consider social factors in using EIS in their work. Finally, the results suggest facilitating conditions variables such as EIS development process, EIS management process and organisational environment are strongly related to the adoption and use of EIS by executives.

\section{CONCLUSIONS AND FUTURE DIRECTION}

The preliminary results of this study suggest that cultural, social, individual and organisational variables are of vital importance in explaining executives' behaviour towards the adoption and use of EIS at the strategic management level. This preliminary result provides future direction in explaining executives' behaviour towards EIS adoption and usage. Perhaps, future findings together with this result will assist system designers to understand the core information processing requirements for executives' tasks for which 
they are building EIS in order to implement appropriate system functionalities to support those tasks. In addition, the model is important in the IS research domain with regards to user behaviour.

\section{Limitations}

There are some limitations associated with the investigation techniques in the pilot. First, the sample size was relatively small, with just 19 participants. This substantially limits the analysis to qualitative analysis and presents some potential for unrepresentative results. Moreover, although there was diversity presented by the respondents of organisations used for the pilot, the pilot study was only limited to two organisations.

\section{Work in progress and Future Directions}

At the time of submitting this paper, 400 questionnaires have been prepared and distributed for the main survey. The questionnaires were mailed out to mainly executives such as CFOs, CEOs, CIOs and other top-level managers of 200 organisations using EIS in Australia. The questionnaires were mailed out in four batches within 2 weeks. The date of each mailed out batch has been recorded. Further, all mailed out questionnaires have been pre-numbered, in order to facilitate the follow-up process of non-responses. In addition, a table to lock in all returns, comments and suggestions to be given by respondents has been developed. The follow-up of non-responses for each batch of questionnaires mailed out is planned to commence three weeks after the initial mail out. Although the questionnaire in the planned follow-up will be exactly the same as the initial ones, a reminder letter will be attached. Moreover, in order to encourage the sample non-respondents to complete and return the follow-up survey, the construction of the reminder letter will be business-like and will place much emphasis on the importance of the survey.

\section{REFERENCES:}

Adams, D., Nelson, R. \& Todd, P. (1992) "Perceived Usefulness, Ease of Use, and Usage of Information Technology: A Replication” MIS Quarterly/June16, 227-247.

Ajzen, I. \& Fishbein, M. (1980) Understanding Attitudes and Predicting Social Behaviour. Englewood Cliffs, NJ: Prentice-Hall.

Bergeron, F., Raymond, L., Rivard, S. and Gara M. (1995) "Determinants of EIS Use: Testing a Behavioural Model", Decision Support Systems, 14, 131-146.

Basu, C., Poindexter, S. and Addo, T. (2000) "Diffusion of Executive Information Systems in Organisations and the shift to Web Technologies", Industrial Management \& Data Systems. MCB University Press (100) 6, 271-276.

Anthony, R.N., Dearden,J. and Govindarajan, V. (1992) Management Control Systems: $7^{\text {th }}$ ed. Erwin.

Dambrot, F. H.,Silling S. M. \& Zook S. (1988) "Psychology of Computer Use: Sex Differences in Prediction of course Grades in a Computer Language Course", Perceptual and Motor Skills, 66, $627-636$.

Davies, L. D. \& Davies F.D. (1990). "The Effects of Training Techniques 7 Personal characteristics on Training End users of information systems,". Journal of management Information System, 7, 93-110.

Davis, F.D. (1989) "Perceived Usefulness, Perceived Ease of Use, and User Acceptance of 
Information Technology", MIS Quarterly (13:3), 319-339.

Davis, F.D. (2001) "Perceived Usefulness, Perceived Ease of Use, and User Acceptance of Information Technology", MIS Quarterly / September (319-339).

Davis, F.D., (1986) “A Technology Acceptance Model for Empirically Testing New EndUser Information Systems: Theory and Results", in MIT Sloan School of Management. Cambridge, MA: Mit Sloan School of Management.

Davis, F. D. (1993) "User acceptance of Information System Technology: System Characteristics, User Perceptions and Behavioural Impacts", International Journal of Man-Machine Studies, Academic Press Limited, 38, 475 - 487.

Davis, F. D., Bagazzi, R. P. \& Warshaw, P. R. (1992) "Extrinsic and Intrinsic Motivation to Use Computers in the Workplace", Journal of Applied Social Psychology, (14) 22, 1111 1132.

Davis, F.D., Bagozzi, R. P. and Warsaw, P.R. (1989) “ User Acceptance of Computer Technology: A Comparison of Two", Management Science (35:8) 982-1003

DeLong, D.W \& Rockart, J.F. (1992) Executive Information Systems: Emergence. Development. Impact: John Wiley \& Son, Inc.,(257-277).

Dishaw M. \& Strong D.(1997). Extending Technology Acceptance Model. Retrieved $27^{\text {th }}$ September, 2003 from://hsb.baylor.edu/ramsower/ais.ac.97/papers/dishaw.htm

Ditsa, G. (2002) Executive Information Systems Use in Organisation Contexts: An Exploratory Study in Issues and Trends of IT Management in Contemporary Organisations, Idea Group Publishing London, 182-191.

Ditsa, G. (2003). Executive Information Systems Use in Organisational Contexts: An Exploratory User Behaviour Testing. Information Management: Support Systems \& Multimedia Technology IRM Press London (109-155).

Elkerton, J. and Williges, R. C. (1984) "Information Retrieval Strategies in a File-Search Environment", Human Factors, 26, 171-184.

Elkordy, M.M. (2000) “An Integrated Model of EIS Use”, in Proceedings of 2000 Information Resources Management Association, International Conference Anchorage, Alaska, USA, 624-627.

Fishbein, M. (1979) “A Theory of Reason Action: Some applications and Implications”, In Nebraska Symposium on Motivation, H. Howe and Page (Edn). University of Nebraska Press, Lincoln, NB. 65-116.

Fishbein, M. and Ajzen, I.(1975) Belief, Attitude, Intention and Behaviour: An Introduction to Theory and Research: Addison-Wesley, Reading, MA.

Fitzgerald, B. \& Murphy, C. (1994) “The EIS Paradox: Putting the Executive into Executive Information System”, Journal of information Technology Vol. 9 No.4, 288-296.

Fitzgerald, B. (1998) "Executive Information Systems without executives", Proceedings of the $3^{\text {rd }}$ conference of UK Academy for Information systems. Lincoln University, UK McgrawHill (288-310), in Avison. D. \& Edgar Nevill D. (eds.) matching Technology with organisational needs.

Gefen, D. \& Straub, D. (2000) "The relative importance of Perceived Ease of Use in IS Adoption: A Study of E-Commerce Adoption”, Journal of the Association for the Information system 1(8).

Hubona, G. S. \& Jones, A. B (2002) "Modelling the User Acceptance of E-Mail”, Proceedings of the $36^{\text {th }}$ Hawaii International Conference on System Sciences (HISS'03)

Handzic, M. (1997) "The Impact of Information Reliability on Utilisation and Effectiveness of Executive Information Systems", $\mathbf{8}^{\text {th }}$ Australasian Conference on information Systems

Harrison, A.W. \& Rainer Jr. R.K. (1992) “The Influence of individual Differences on Skills in 
End user Computing”, Journal of Management Information Systems, 9, 93-111.

Houdeshel, G. \& Watson, H.J. (1992) Executive Information Systems: Emergence. Development. Impact: John Wiley \& Son, Inc.,(13-31).

Hunt, S. D., Sparkman, R. D., and Wilcox, J. B. (1982) "The pretest in survey research: Issues and preliminary findings", Journal of Marketing Research, 19 (May), 269-273.

Igbaria, M. (1993) "User Acceptance of Microcomputer Technology: An Empirical Test", Omega, (21), 1, 73-90.

Ikart, E.M. (2004) "Factors Influencing Executive Information Systems Adoption and Usage by Organisational Executives", Conference on Information Sciences and Technology Management, July 8-9 2004, Ancient Library of Alexandria, Egypt.

Ikart, E.M. (2004) "A Research Model for the Investigation of Top Management Adoption and Use of Executive Information Systems", Proceedings of The 2004 International Business Information Management Conference July 4 - 6 Amman, Jordan, pp.169-181.

Kelly, F. (1994) "Implementing an EIS (Executive Information System)", Retrieved 23 ${ }^{\text {rd }}$ September2003 from: www.itmweb.com/essay519.htm .

Kling, R. (1991) "Excerpts From 'Social Analysis of Computing: Theoretical Perspectives in Recent Empirical Research", in Dunlop, C. \& Kling eds/ (1991) computerization and Controversy: Value Conflicts and Social Choices Boston: Academic Press, Part11, 150166.

Kotter, J.P.(1982). The General Manager: The Free Press, New York.

Kraemer, K. L, Danziger, J. N, Dunkle, D. E \& King J . K., (1993) "The usefulness of computer-based information systems to public managers", MIS Quarterly June, 129-148.

Kwon, H. S. and Chidambaram, L. (2000) "A Test of Technology Acceptance Model: The Case of Cellular Telephone Adoption", Proceedings of the $\mathbf{3 3}^{\text {rd }}$ Hawaii International Conference on System Sciences, IEEE.

Leidner, D. \& Elam, J. (1994) "Senior and Middle Management Use of EIS: A Descriptive Study", Proceeding of the Twenty-Seventh Annual Hawaii International Conference on System Sciences, 135-144.

Liang, L. Y. and Miranda, R. (2001) Dashboards: Executive Information Systems for the Public Sector: Government Officers Association USA.

Lim, K. S. (2002) "Validation of the Technology Acceptance Model with Academic Users", Decision Sciences Institute Annual Meeting Proceedings, 1402- 1407.

Lucas, H. C. (1978) "Empirical Evidence for a Description Model of Implementation", MIS Quarterly, 2, 27-52.

Malhotra, Y., and Galletta, D. (1999) "Extending the Technology Acceptance Model to Account for Social Influence: Theoretical Bases and Empirical Validation”, Proceeding of the $32^{\text {nd }}$ Hawaii International Conference on System Sciences IEEE.

Mao, E. (2002) “An Investigation of IT Usage over Time”, Eight Americas Conference on Information Systems, pp.1307-1312

Mathieson, K. (1991) "Predicting user intentions: Comparing the technology Acceptance Model with the Theory of Planned Behaviour", Information System Research, 2 (3), 173191.

McBride, N. (1997) “The Rise and Fall of an Executive Information System: a Case Study", Information Systems Journal (1997) 7, 277- 287.

Mintzberg, H. (1973) The Nature of Managerial Work: Harper \& Row Publishers London.

Money, W. \& Turner, A. (2004) “Application of Technology Acceptance Model to a Knowledge Management Systems", Proceeding of the $37^{\text {th }}$ Hawaii International Conference on System Science. IEEE. 
Moore, G. C \& Benbasat, I. (1991) "Development of an Instrument to Measure the Perceptions of Adopting an Information Technology Innovation”, Information System Research, 2, (192-222).

Nandhakumar, J. \& Jones M. (1997) "Designing in the Dark: The Changing User-Developer Relationship in Information Systems Development", Proceedings of the Eighteenth International Conference on Information Systems, Atlanta Georgia, 75-89.

Nord J. and Nord G., (1995) "Executive Information System: A study and Comparative Analysis”, Information \& Management 29, 95 - 106 Elsevier Science B.V.

Poon, P. \& Wagner, C. (2001) "Critical Success Factors Revisited: Success and Failure Cases of Information Systems for Senior Executives”, Decision Support Systems 30, 393-418 Elsevier Science B.V.

Rainer, Jr. R. \& Watson, H.,(1995) "What Does It Takes for Successful Executive information Systems?”, Decision Support Systems (14), Elsevier Science B.V., 147-156.

Raisinghani, M. S. \& Schkade L. (1997) "Strategic Decision Making: A Framework for Multicriteria Decision analysis of Technology Investigation and a Field Survey", Retrieved $27^{\text {th }}$ October 2003 from://hsb.baylor.edu/ramsower/ais.ac.97/papers/raising2.thm

Robey, D. (1979) "User Attitude and Management Information System Use", Academy of Management Journal, 22(3), 527-538.

Rockart J.F. \& Treacy M.E. (1992) Executive Information Systems: Emergence. Development. Impact: John Wiley \& Son, Inc.,(3-12).

Rockart J. F. \& DeLong D. W. (1992) Executive Information Systems: Emergence. Development. Impact: John Wiley \& Son, Inc., (315-325).

Rogers, E.M. (1986) Communication Technology - The New Media In Society. New York, NY: The Free Press

Rosson, M.B. (1983) "Patterns of Experience in Text Editing", Proceedings of the CHI'83 Human Factors in Computing Systems, 171-175.

Salmeron, J. L (2002) "EIS Evolution in Large Spanish Businesses", Information \& Management, 40, 41-50, Elsevier Science B.V.,

Seeley, M. \& Targett D., (1999) "Patterns of Senior Executives' Personal Use of Computer", Information Management (35), 315-330, Elsevier Science B.V.

Singh S. K, Watson H. J. \& Watson R. T, ( 2002) "EIS Support for Strategic Management Process", Decision Support Systems (33), 71-85. Elsevier Science B.V.

Stein A., \& Nasib Z., (1997) "Executive Computing a Benefit Matrix", Retrieved $9^{\text {th }}$ September 2001 from ://hsb.baylor.edu.ramsower/ais.ac.97/papers/stein.htm.

Srivihok, A. (1999). "Understanding Executive Information Systems Implementation: an Empirical Study of EIS Success Factors", Proceedings of the 32th Hawaii International Conference on System Sciences, IEEE.

Szajna, B. (1993) "Determining Information System Usage: Some Issues and Examples", Information and Management (25), 147-154. Elsevier Science B.V.

Taylor, S. and Todd, P.A (1995) "Understanding Information Technology Usage: A Test of Competitive Models", Information System Research, 6(2)144-176

Thierauf R., (1991). Executive Information Systems: A Guide for Senior Management and MIS Professionals: Quorum Book New York.

Thodenius B., (1995) "The Use of Executive Information Systems in Sweden", CEMS Academic Conference- Recent Development in Economics \& Business Administration" at the Wirtschaftsuniversitat WIen, Austria, April 20-22.

Thompson, R.L. Higgins, C.A and Howell, J.M, (1991) "Personal Computing Towards a Conceptual Model of Utilisation", MIS Quarterly, 15(1) 125-143 
Triandis H.C. (1979). Values, Attitudes, and Interpersonal behaviour. Nebraska Symposium on Motivation: Beliefs, Attitude, and Values: University of Nabraska Press, 195-259.

Triandis H.C., (1971) Attitude and Attitude Change: John Wiley \& Son, Inc. New York USA.

Turban E. (1993). Decision Support Expert Systems: Management Support Systems: Macmillan Publishing Company, New York.

Venkatesh V., Morris M., Davis G.B. \& Davis F.D. (2003) "User Acceptance of Information Technology: Toward A Unified View”, MIS Quarterly Vol.27 No.3, pp. 425-478.

Venkatesh, V. and Davies F.D. (1996) "A model of antecedents of perceived ease of use: Development and test", Decision Sciences, 27(3), 451-482.

Verenikina I. \& Gould E. (1997) "Activity Theory As A Framework for Interface Design”,. ASCILITE December 7-10’97.

Vlahos G.E., Ferratt T. W. \& Knoepfle G., (2000) "Use and Perceived Value of ComputerBased Information Systems in Supporting the Decision Making of German Managers", SIGCPR Evanston Illinois USA, ACM, (111-123).

Watson, H. J., Rainer Jr. R.K. \& Koh C. E., (1991) “ Executive Information Systems: A Framework for development and Survey of Current Practices”, MIS Quarterly, March, 13-30.

Westen, D. (1996) Psychology Mind, Brain, \& Culture. John Weiley \& Son, Inc. New York USA.

Wheeler, F. P. (1996). "The potential for Executive Information Systems to Support the Management of Business Reconfiguration", Retrieved $20^{\text {th }}$ September 2002 from: //www.shu.ac.uk/schools/fsl/fisjnl/vol1996/pprs1996/p96003.htm

Wilt F., (1991) Top Officers Don't Use Executive Info Systems in National Underwriter Life \& Health/Financial Services.

Yager S. E. (1997) "The Role of Information Technology Support Mechanisms in Coordination Management for Virtual Organisations", September $28^{\text {th }} 2003$ from://hsh.baylor.edu/ramsower/ais.ac.97/papers/yager.htm

Young D. \& Watson H. J., (1995) "Determinates of EIS Acceptance”,. Information \& Management 29, (153-164). Elsevier Science B.V.

Zmud, R. W.(1979) "Individual Differences \& MIS success: A Review of the Empirical literature," Management Science, 25, 966-979. 